\title{
The relationships that matter: social network site use and social wellbeing among older adults in the United States of America
}

\author{
REBECCA P. YU*, RYAN J. MCCAMMON $\dagger$, NICOLE B. ELLISON $\dagger$ \\ and KENNETH M. LANGA§
}

\begin{abstract}
An increasing number of middle-aged and older Americans are using social network sites (SNSs), but little research has addressed how SNS use is associated with social wellbeing outcomes in this population. Using a nationally representative sample of 1,620 Americans older than $5^{\mathrm{o}}$ from the 2012 Health and Retirement Study (HRS), we examine the relationship between older adults' SNS use and social wellbeing associated with non-kin and kin relations and explore how these associations vary by age. Results of ordinary least-squares regression analyses suggest that SNS use is positively associated with non-kin-related social wellbeing outcomes, including perceived support from friends $(\beta=0.13 ; p<0.001 ; \mathrm{N}=460)$ and feelings of connectedness $(\beta=0.10 ; p<0.001 ; N=463)$. Regression models employing interaction terms of age and SNS use further reveal that SNS use contributes to feelings of connectedness to a greater extent as people age $(\beta=0.10 ; p<0.001 ; \mathrm{N}=463)$. Of all kin-related social wellbeing outcomes, SNS use only predicts increased perceived support from children $(\beta=0.08 ; p<0.05 ; \mathrm{N}=410)$, and age negatively shapes this relationship $(\beta=-0.14 ; p<0.001 ; \mathrm{N}=410)$. As older people engage with an increasingly smaller and narrower network with a greater proportion of kin contacts, our results suggest that SNS use may help older adults access differential social benefits throughout later life.
\end{abstract}

KEY WORDS - social network site, social support, feelings of isolation, feelings of connectedness, social wellbeing.

* Communication Studies, University of Michigan, Ann Arbor, USA.

$\dagger$ Division of General Medicine, Department of Medicine, University of Michigan, Ann Arbor, USA.

+ School of Information, University of Michigan, Ann Arbor, USA.

$\S$ Division of General Medicine, VA Center for Clinical Management Research, Institute for Social Research, Institute of Gerontology, Institute for Healthcare Policy and Innovation, University of Michigan, Ann Arbor, USA. 


\section{Introduction}

As early adopters of social network sites (SNSs) were mainly young adults, research on SNS use and its effect on social wellbeing has expanded dramatically recently, primarily employing samples of younger or early middle-aged adults (e.g. Burke, Marlow and Lento 2010; Ellison, Steinfield and Lampe 2007, 2011). SNSs, defined as 'networked communication platform[s] in which users have uniquely identifiable profiles ... can publicly articulate connections ... and can consume, produce, and/or interact with streams of user-generated content' (Ellison and boyd 2013: 158) have quickly gained popularity among middle-aged and older adults in recent years. The Pew Internet and American Life Project reports that among internetusing adults aged 50-64 in 2014, 64 per cent used SNSs (Duggan et al. 2015 ). The adoption rate of SNSs among internet users aged 65 years or older has quadrupled from 13 per cent in 2009 to $5^{6}$ per cent in 2014 in the United States of America (USA) (Duggan et al. 2015). Despite this rapid adoption among older adults, the outcomes associated with SNS use in this population remain largely unexplored. As older adults often have reduced social engagement due to factors associated with age, such as loss of social roles, contacts and physical abilities, and it is widely recognised that social relationships increase older adults' physical and mental health (Litwin and Shiovitz-Ezra 2011; Steptoe et al. 2013), it is an appropriate time for scholars to consider how use of SNSs may help shape older adults' social wellbeing, broadly defined as perceived social support and loneliness.

In this study, we use survey data from a nationally representative sample of Americans over the age of $5^{\circ}$ from the 2012 HRS to examine the relationship between SNS use and relation-based social wellbeing, which includes perceptions of support from children, other immediate family and friends, as well as dimensions of loneliness (i.e. feelings of isolation and feelings of connectedness). The theoretical rationale for this approach stems from the fact that SNSs connect users to both kin and non-kin social contacts (Bakshy et al. 2012), both of which are essential for older adults' health although they meet different interpersonal needs (Weiss 1973) and may offer different kinds of social resources (Ellison, Steinfield and Lampe 2007, 2011). Thus, when exploring benefits associated with SNS use, it is important to consider specific types of relational benefits, as opposed to aggregate measures of overall relational benefits. Furthermore, as age is associated with decreased physical health (Cornwell and Waite 2009), smaller social networks (Cornwell, Laumann and Schumm 2008) and increased barriers to technology use (Lee, Chen and Hewitt 2011), these age differences may be reflected in the social wellbeing outcomes 
associated with SNS use. Thus, we further examine how the association between SNS use and types of social wellbeing might differ by age. In doing so, our study sheds light on SNS use and its implications for social wellbeing vis-à-vis different relation types while illuminating how these associations differ across later life stages.

\section{Perceptions of social support}

The concept of social support describes resources embedded in interactions within a social network that serve to stave off and/or minimise the negative effects of stress and enhance psychological and physical health (Cohen 2004; Thoits 1995). Individuals often receive different types of support from kin and non-kin relations (Weiss 1974). Kin contacts, such as family members, are characterised by obligatory, ritualised interactions and typically provide access to substantive forms of support, such as physical and emotional assistance in time of illness (Shanas 1979). Non-kin relationships, on the other hand, are voluntary and reciprocal in nature. Interactions with non-kin ties, such as friends, are often desired by older adults because such relations are an important source of enjoyment and feelings of autonomy (Larson, Mannell and Zuzanek 1986). Because the two types of relationships perform different functions for individuals, empirical evidence shows that older adults who are embedded in a diverse network that can provide support from various sources have better mental health than those in a more restricted network (Fiori, Antonucci and Cortina 2006; Litwin and Shiovitz-Ezra 2011). As both kin and non-kin ties exist in individuals' SNS networks (Bakshy et al. 2012 ), we examine how older adults' SNS use is associated with perceived support from kin (children and other family) and non-kin (friends) ties.

\section{SNS use and perceived support from kin ties: children and other family}

Older adults use SNSs to connect with family members. Unlike younger adults who adopt SNSs to connect with their peers (boyd 2007), the primary motivation for older adults' adoption of SNSs is to connect with family members such as adult children, relatives and grandchildren (Bell et al. 2013; Brandtzæg, Lüders and Skjetne 2010; Goode 2011). SNSs allow older adults to keep up with their children and other family members' lives and to offer and possibly receive support from afar. One study examining interactions between parents and their adult children on Facebook found that their direct exchanges were 'full of affection, advice, phone calls, and [communication about] grandchildren' (Burke, Adamic 
and Marciniak 2013:47). In addition to their own children, older adults often 'friend' immediate family members, such as siblings, parents, cousins and grandchildren, on SNSs (Bell et al. 2013), thus SNS use can increase older adults' awareness of what happens in these family members' lives (Brandtzæe, Lüders and Skjetne 2010; Goode 2011).

However, SNSs are one of the ways in which older adults connect with family members. Haythornthwaite (2005) proposes the idea of 'media multiplexity' which suggests that as tie strength increases, the number and the type of information exchanged and the range of media platforms used to communicate increases accordingly. Consistent with this perspective, there is evidence that, for serious issues, older adults use other communication channels, such as phone calls, to continue the conversation outside SNSs (Erickson 2011). Because multiple channels are available to communicate with kin ties, SNS use may have less impact on older adults' relations with kin whom they meet in person or speak on the phone with frequently. Indeed, research shows that those who use Facebook as the primary mode of communication to maintain relationships are more likely to percieve that the site positively impacts the quality of these relationships, compared to those who use multiple channels to maintain the relationships (Vitak 2014). Moreover, as older generations tend to prefer 'richer' forms of communication that require time, dedication and reciprocity (e.g. in-person or phone interactions) (Lindley, Harper and Sellen 2009), older SNS users may be less likely to use SNSs (comparatively 'leaner' media) to communicate with older family members who are in a similar age range and share similar preferences in modes of communication, such as siblings and cousins. Based on the principle of media multiplexity (Haythornthwaite 2005), older adults' SNS use may not be associated with perceptions of support from children or other family members. Thus, we propose:

- Hypothesis 1 ( $\left.\mathrm{H}_{1}\right)$ : Among older adults, SNS use will not be significantly related to perceived support from kin ties, namely (Hia) children and (Hib) other family members.

\section{SNS use and perceived support from non-kin ties: friends}

SNSs enable users to create 'social supernets' and to manage larger networks with low effort (Donath 2007), which may help older adults to increase the size of their social networks and thus gain access to a wider range of social support. SNS research on younger adults has suggested that SNSs provide an ideal platform for maintaining relationships with non-kin ties, such as keeping in touch with an old friend (Lampe, Ellison 
and Steinfield 2006) or maintaining relationships with people you may not get to see very often (Joinson 2008). Similarly, given SNSs' technical and social options, such as search features and recommendation algorithms, older adults often use SNSs to reconnect with dormant ties or old acquaintances with whom they have lost touch, such as former classmates and childhood neighbourhood friends (Quinn 2013). In addition to these forms of reconnection, SNSs are also used to facilitate new connections among older adults. In one interview study, older immigrants became friends with the offspring of their old acquaintances in the process of reconnecting via SNSs (Khvorostianov, Elias and Nimrod 2012). There is also evidence that SNSs connect older adults to those in similar professions and help create business opportunities (Goode 2011). Older adults use SNSs to keep up with the activities of friends and exchange messages related to life events (e.g. sending birthday wishes) (Erickson 2011). Given that establishing connections with social contacts and then engaging in relationship maintenance activities with them is associated with higher perceived levels of social capital among adults (Ellison et al. 2014), we expect that SNS use by older adults will enable them to connect with weaker ties (non-kin) and that these activities may be associated with exchanges of social support. Thus, we expect that:

- Hypothesis 2 (H2): Among older adults, SNS use will be positively associated with perceived support from non-kin ties, namely friends.

\section{Kin- and non-kin-related dimensions of loneliness: feelings of isolation and connectedness}

Loneliness describes subjective experiences or feelings that one's social needs are not being met with regard to the quantity or the quality of one's social relationships (Peplau and Perlman 1982), which can negatively influence older adults' physical health, such as decreased cognitive functioning (Tilvis et al. 2004), increased blood pressure (Hawkley and Cacioppo 2010) and increased mortality (Shiovitz-Ezra and Ayalon 2010). Because different types of relationships can meet different relational needs, instead of treating loneliness as one uniform aversive experience, scholars have differentiated loneliness into two types (Weiss 1973). One type of loneliness is associated with kin ties, resulting from the lack of close attachment to intimate others, whereas the other form is related to non-kin relations, stemming from the absence of connection to a social network of friendships.

The 20-item revised UCLA Loneliness Scale (R-UCLA scale; Russel, Peplau and Cutrona 1980) is perhaps the most frequently used loneliness 
measure. Consistent with Peplau and Perlman's (1982) conceptualisation of loneliness, the R-UCLA scale measures emotional responses to the discrepancies between desired and achieved social interactions (Robinson, Shaver and Wrightsman 1991). While prior factor analysis of the R-UCLA scale has identified different factor structures, some factor analytic studies (e.g. Hawkley, Browne and Cacioppo 2005; McWhirter 1990) show that the R-UCLA scale broadly consists of feelings of isolation and connectedness. Similar to the theoretical typology of loneliness (Weiss 1973), the two broad dimensions of loneliness are associated with kin and non-kin interactions, such that feelings of isolation describe a sense of being distant from intimate others or an absence of significant others, whereas feelings of connectedness suggest a sense of having a social network with which to connect or a group to which one belongs. There is evidence that the two broad dimensions in the R-UCLA scale are associated with interactions with different kinds of ties. For example, Hawkley, Browne and Cacioppo (2005) found that being married was negatively associated with feelings of isolation, but was not predictive of feelings of connectedness.

Prior work has explored how the amount of internet use (e.g. frequency of going online) relates to dimensions of loneliness among older adults (e.g. Cotten, Anderson and McCullough 2013), but few studies to date have focused on how social use of the internet, and SNS use in particular, predict dimensions of loneliness. One exception is Ahn and Shin's (2013) study, which used an adult sample and found that using the internet to communicate with others (e.g. posting comments and exchanging messages on SNSs) was associated with increased feelings of connectedness but was not predictive of feelings of isolation. This pattern of findings is consistent with other research because stronger ties typically use multiple communication channels (Haythornthwaite 2005), and thus SNSs may not play an important role in alleviating kin relation-based loneliness (feelings of isolation) when compared to other forms of interaction. In contrast, because SNSs can connect older adults to weaker ties such as past and new acquaintances (Khvorostianov, Elias and Nimrod 2012; Quinn 2013) and may become the primary mode to get in touch with these non-kin ties, older adults may experience increased feelings of connectedness associated with their SNS use. Thus, we suggest:

- Hypothesis $3\left(\mathrm{H}_{3}\right)$ : Among older adults, SNS use will not be significantly associated with loneliness related to kin ties, namely feelings of isolation.

- Hypothesis $4\left(\mathrm{H}_{4}\right)$ : Among older adults, SNS use will be positively associated with loneliness related to non-kin ties, namely feelings of connectedness. 


\section{SNS use and social wellbeing in later life}

Finally, we investigate whether and how the relationships between SNS use and the two forms of social wellbeing - non-kin and kin-related social wellbeing - vary by age in the older population. First, while we hypothesise that SNS use contributes to non-kin-based social wellbeing, including perceived support from friends and feelings of connectedness, it is not clear whether and how these positive relationships vary throughout the later lifespan. The divergent views on why social engagement decreases with age - involuntary and voluntary loss hypotheses - lead to contrary expectations about whether and how the associations between SNS use and non-kin-related social wellbeing differ by age. The involuntary loss hypothesis, based on the Continuity Theory (Atchley 1989), suggests that decreased social engagement with age, resulting from involuntary causes related to age such as mandatory retirement, bereavement and health declines, often prompts older adults to cultivate new social connections to adapt to later-life loss of social roles and contacts. For example, a national longitudinal study in the USA shows that when losing confidantes, older adults tend to maintain their network by adding new ones (often weak ties). The network growth is associated with better health outcomes (Cornwell and Laumann 2015). According to the involuntary loss hypothesis, SNS use may be especially beneficial for older adults to connect with non-kin relations and possibly receive support from them in order to compensate for the loss of social roles and contacts in the ageing process. In this sense, age may positively shape the relationship between SNS use and non-kin-related social wellbeing.

The voluntary loss hypothesis, on the other hand, suggests that older adults deliberatively narrow their social networks due to the reduced resources in later life (Carstensen 1993). Socioemotional Selectivity Theory (SST; Carstensen 1993) suggests that an individual's perceptions of his or her remaining time to live determine the priority of goals. As perceptions of the time horizon become more limited throughout mid-life and into old age, older adults tend to withdraw deliberatively from social contact in peripheral relationships, while maintaining or increasing involvement in relationships with strong ties (often kin ties) to optimise emotional wellbeing (Conway et al. 2013; Lang 2000). As individuals increasingly focus on kin relationships while voluntarily withdrawing from weak relationships (often non-kin) with age, they may become less motivated to connect to and interact with non-kin ties through SNSs. Thus, age may not or even negatively shape the relationship between SNS use and non-kin-related social wellbeing. Given the two divergent perspectives, we pose the following research question: 
- Research Question 1 (RQ1): Will the associations between SNS use and non-kin-related social wellbeing, namely perceived support from friends and feelings of connectedness, differ by age?

Second, it is also unclear whether and how the associations between SNS use and kin-related social wellbeing-perceived support from children and other family, and feelings of isolation - are stratified by age in the older population. Because people use multiple channels to communicate with strong ties (Haythornthwaite 2005), habitual communication practices that are associated with age may influence the role of SNSs in maintaining kin relations among older adults. Qualitative research has suggested that older generations tend to prefer 'richer' forms of communication methods that can reveal more personal cues, such as the telephone (Dickinson and Hill 2007). For instance, a focus group study with people aged $55^{-81}$ found that while all participants preferred communication channels that were more personalised, more focused and more persistent (Lindley, Harper and Sellen 2009), younger participants were more willing to tailor communication methods based on the preferences of the people they communicated with than older participants. Because age is associated with increased attitudinal and physical barriers to technology use (Charness and Boot 2009; Lee, Chen and Hewitt 2011 ), these communication preferences may be more influential in guiding the communication practices of the older-old than the younger-old adults, suggesting that as users age, SNSs may play less of a role in facilitating kin-related social wellbeing. However, there has been no systematic effort that uses representative samples to explicate whether and how communication practices with kin ties differ by age. Due to the lack of scholarship addressing this issue, we pose the following research question. (All proposed hypotheses and research questions are summarised in Table 1.)

- Research Question 2 (RQ2): Will the associations between SNS use and kin-related social wellbeing, namely perceived support from children and other family, and feelings of isolation, differ by age?

\section{Methods}

\section{Sample}

To address our research questions, we used data from the 2012 wave of the HRS, a nationally representative longitudinal survey of more than 37,000 Americans over the age of $5^{\mathrm{O}}$ in 23 , ooo households (Sonnega et al. 2014). The HRS is comprised of six cohorts who entered the study in different calendar years. Once eligible respondents enter the study, they are 
T A в L E 1 . Summary of hypotheses $(H)$ and research questions $(R Q)$

\begin{tabular}{|c|c|c|c|}
\hline & Predictor variable & Outcome variable & Prediction \\
\hline $\mathrm{H}_{1}$ & SNS use & $\begin{array}{l}\text { Perceived support from kin ties } \\
\text { (children and other family) }\end{array}$ & Non-significant \\
\hline $\mathrm{H}_{2}$ & SNS use & $\begin{array}{l}\text { Perceived support from non-kin ties } \\
\text { (friends) }\end{array}$ & Positive \\
\hline $\mathrm{H}_{3}$ & SNS use & $\begin{array}{l}\text { Loneliness related to kin ties } \\
\text { (feelings of isolation) }\end{array}$ & Non-significant \\
\hline $\mathrm{H}_{4}$ & SNS use & $\begin{array}{l}\text { Loneliness related to non-kin ties } \\
\text { (feelings of connectedness) }\end{array}$ & Positive \\
\hline RQ1 & Age $\times$ SNS use & $\begin{array}{l}\text { Non-kin-related social wellbeing } \\
\text { (perceived support from friends and } \\
\text { feelings of connectedness) }\end{array}$ & - \\
\hline $\mathrm{RQ}_{2}$ & Age $\times$ SNS use & $\begin{array}{l}\text { Kin-related social wellbeing } \\
\text { (perceived support from children and } \\
\text { other family, and feelings of isolation) }\end{array}$ & - \\
\hline
\end{tabular}

Note: SNS: social network site.

interviewed every two years. The sample for each cohort was derived from the same stratified multi-stage area probability design in which Blacks, Hispanics and residents of the state of Florida were oversampled (Heeringa and Connor 1995).

The HRS sample used in this study includes 1,620 respondents (unweighted), who were randomly selected from all HRS respondents and administered the three-minute technology module, which included questions about SNS use. Among the 1,620 respondents, 607 randomly selected respondents answered the Psychosocial and Lifestyle Questionnaire. Instruments from the Psychosocial and Lifestyle Questionnaire employed in this study included loneliness, perceived support from children, other family and friends, number of close social ties, and frequency of in-person and phone interactions with social ties. Because some respondents did not have any living children, other immediate family or friends, the number of responses for related variables may be lower than 607 . Coding procedures for these variables are included in the measures section. We summarise descriptive statistics of all the variables in Table 2.

\section{Measures}

Predictor variable. SNS use: SNS use was included in the technology-use module, framed as: 'Do you use social networks such as Facebook or Twitter?' The response was dichotomous $(1=$ yes, $\mathrm{O}=\mathrm{no})$.

Outcome variables. Perceived support from children, other immediate family and friends: Perceptions of support from three different sources were measured 
T A B L E 2. Descriptive statistics of all variables for social network site (SNS) users and non-users

\begin{tabular}{|c|c|c|c|c|c|c|c|c|c|c|}
\hline & \multicolumn{3}{|c|}{ Full sample } & \multicolumn{3}{|c|}{ SNS users } & \multicolumn{3}{|c|}{ SNS non-users } & \multirow[b]{2}{*}{$t$ or $\chi^{2}$} \\
\hline & Mean or $\%$ & SD & $\mathrm{N}$ & Mean or $\%$ & SD & $\mathrm{N}$ & Mean or $\%$ & SD & $\mathrm{N}$ & \\
\hline Age $\left(5^{2-}-9^{8}\right)$ & 65.27 & 9.80 & 1,620 & 61.39 & 7.66 & 437 & 66.97 & 10.15 & 1181 & $11.25^{* * *}$ \\
\hline Years of education $(\mathrm{o}-17)$ & 13.26 & 2.94 & 1,620 & 14.23 & 2.22 & 437 & 12.83 & 3.11 & 1181 & $9.04^{* * *}$ \\
\hline Gender (female) & $5^{1.5^{0}}$ & - & 1,620 & 59.82 & - & 437 & $47 \cdot 9^{1}$ & - & 1181 & $11.16 * *$ \\
\hline Marital status (married) & 63.28 & - & 1,620 & 66.69 & - & 437 & 61.82 & - & 1181 & 1.27 \\
\hline Race (non-Hispanic White) & 82.08 & - & 1,620 & $89 \cdot 54$ & - & 437 & 78.86 & - & 1181 & $24.9^{6 * * *}$ \\
\hline Income quintile $(\mathrm{o}-4)$ & 2.21 & 1.44 & 1,620 & 2.59 & 1.37 & 437 & 2.04 & 1.45 & 1181 & $4.55^{* * *}$ \\
\hline Wealth quintile $(\mathrm{O}-4)$ & 2.14 & 1.39 & 1,620 & 2.26 & 1.36 & 437 & 2.09 & 1.40 & 1181 & 1.73 \\
\hline Employment status (employed) & $45 \cdot 94$ & - & 1,620 & 60.06 & - & 437 & $39 \cdot 76$ & - & 1181 & $33.59 * * *$ \\
\hline Cognitive functioning $(\mathrm{o}-27)$ & $15 \cdot 53$ & $4 \cdot 5^{1}$ & 1,620 & 16.97 & $3 \cdot 74$ & 437 & 14.91 & 4.68 & 1181 & $7 \cdot 31^{* * *}$ \\
\hline Self-rated health $(1-5)$ & 3.27 & 1.08 & 1,619 & $3 \cdot 47$ & 1.11 & $43^{6}$ & 3.19 & 1.05 & 1181 & $4 \cdot 37^{* * * *}$ \\
\hline Number of close contacts $(\mathrm{o}-3 \mathrm{O})$ & $9 \cdot 3^{2}$ & 6.03 & 492 & 8.02 & $4 \cdot 4^{\circ}$ & 144 & $9 \cdot 99$ & 6.63 & $34^{8}$ & $6.07 * * *$ \\
\hline Meeting $\left(3^{-18}\right)$ & 11.39 & 2.87 & 490 & 11.23 & 2.49 & 139 & $11.4^{6}$ & 3.04 & $35^{1}$ & 1.16 \\
\hline Speaking $(3-18)$ & $13 \cdot 53$ & 2.65 & 496 & 13.28 & 2.76 & 141 & 13.66 & 2.59 & 355 & 1.95 \\
\hline Support from children $(3-12)$ & $9 \cdot 47$ & 2.23 & 532 & 9.61 & 1.98 & 140 & $9 \cdot 4^{1}$ & 2.33 & 392 & 0.33 \\
\hline Support from family $(3-12)$ & $8.5^{6}$ & 2.61 & $55^{6}$ & 8.71 & $2.5^{2}$ & $15^{2}$ & 8.48 & 2.64 & 404 & 2.00 \\
\hline Support from friends $(3-12)$ & 9.10 & 2.29 & 544 & $9 \cdot 54$ & 2.11 & 154 & 8.88 & 2.34 & 390 & $5.86 * * *$ \\
\hline Feelings of isolation $(4-12)$ & 6.02 & 2.18 & 607 & 5.87 & 1.99 & 160 & 6.09 & 2.26 & 447 & $2.25^{*}$ \\
\hline Feelings of connectedness $(7-21)$ & 17.12 & $3 \cdot 43$ & 606 & $17 \cdot 72$ & 3.10 & 159 & 16.86 & $3 \cdot 54$ & 447 & $5.10^{* * * *}$ \\
\hline
\end{tabular}

Notes: Sample sizes reported are unweighted. Reported means and percentages are survey-adjusted and weighted. Comparisons made between SNS users and non-users, between means $\left(t\right.$-test) and percentages $\left(\chi^{2}\right.$-test $)$.

Significance levels: $* p<0.05, * * p<0.01, * * * p<0.001$. 
by three items, framed respectively as: 'How much do they really understand the way you feel about things?', 'How much can you rely on them if you have a serious problem?' and 'How much can you open up to them if you need to talk about your worries?' Items were asked in loops in reference to children (reliability $=0.89$ ), other immediate family (e.g. siblings, parents, cousins or grandchildren $)($ reliability $=0.93)$ and friends $($ reliability $=0.91) .{ }^{1}$ The response options ranged from 1 (not at all) to 4 (a lot). Composite measures of perceived support from children, other family and friends were created by summing the three items for each type of support, resulting in scores that could range from 3 to 12 . Those who did not have children, other immediate family or friends were excluded from analyses using each of these measures, respectively.

Dimensions of loneliness: To assess loneliness, the HRS Psychosocial and Lifestyle Questionnaire administered 11 items from the 20-item R-UCLA scale. The question was framed as, 'How much of the time do you feel [state]?' The 11 states included items such as 'you lack companionship', 'left out' and 'that there are people you can turn to'. The response scale ranged from 1 (hardly ever or never) to 3 (often). Factor analysis was conducted to identify dimensions of meanings in the 11 -item loneliness scale. First, we performed the exploratory factor analysis (EFA) on a randomly divided sample $(\mathrm{N}=282)$ using FACTOR (Lorenzo-Seva and Ferrando 2006), an EFA software package that can analyse polychoric correlations. To determine factor retention, we employed Parallel Analysis based on Minimum Rank Factor Analysis (PA-MRFA; Timmerman and LorenzoSeva 2011), with oblique rotation which allows for the possibility of correlated factors. PA-MRFA results show that the real data percentage of variance for the first two factors $(64.2$ and 16.2) exceeded the mean of the random percentage of variance (18.4 and 16.2), while only the first factor's real data variance exceeded the $95^{\text {th }}$ percentile of the random common variance extracted (21.2). Overall, results provided some support for a two-factor structure. The two factors were highly correlated $(r=0.59)$. The item loadings from the rotated pattern matrix are presented in Table 3. Second, a confirmatory factor analysis (CFA) on the remaining data set $(\mathrm{N}=282)$ was conducted to test the reliability of the structure identified in the EFA using Mplus 7.3. We employed the WLSMV estimator (Weighted Least Square Parameter Estimates), which uses a diagonal weight matrix with standard errors and mean and a variance-adjusted chisquare test statistic that uses a full weight matrix (Muthén and Muthén 1998-2012). The results of the CFA indicate a reasonably good fit of the two-factor solution to the data $\left(\chi^{2}(34, \mathrm{~N}=282)=139.40\right.$, and with Tucker-Lewis Index $=0.98$, Comparative Fit Index $=0.98$, Root Mean Square Error of Approximation=o.og). The composite measures of 
T A B L E 3 . Factor loadings of the I I-item loneliness scale

\begin{tabular}{|c|c|c|c|c|}
\hline & \multicolumn{2}{|c|}{$\begin{array}{l}\text { Exploratory factor } \\
\text { analysis } \\
(\mathrm{N}=282)\end{array}$} & \multicolumn{2}{|c|}{$\begin{array}{l}\text { Confirmatory factor analysis } \\
(\mathrm{N}=\mathbf{2 8 2})\end{array}$} \\
\hline & Factor 1 & Factor 2 & Factor 1 & Factor 2 \\
\hline Lack companionship & -0.11 & 0.89 & & $0.82(0.04)$ \\
\hline Feel left out & 0.03 & 0.88 & & $0.86(0.03)$ \\
\hline Feel isolated from others & 0.08 & 0.85 & & $0.87(0.03)$ \\
\hline Alone & 0.05 & 0.83 & & $0.83(0.04)$ \\
\hline In tune with others & o.6o & 0.01 & $0.5^{\circ}(0.05)$ & \\
\hline People can talk to & 0.84 & 0.09 & $0.93(0.02)$ & \\
\hline People can turn to & 0.82 & 0.10 & $0.95(0.02)$ & \\
\hline People understand you & 0.88 & -0.02 & $0.87(0.02)$ & \\
\hline People feel close to & 0.94 & -0.08 & $0.83(0.03)$ & \\
\hline Feel part of group & 0.85 & -0.01 & $0.81(0.03)$ & \\
\hline A lot in common with friends & 0.74 & 0.01 & $0.79(0.03)$ & \\
\hline
\end{tabular}

Notes: Standard errors are in parentheses. Factor-specific item loadings are indicated in boldface.

feelings of isolation and connectedness were created by summing the items for each dimension of loneliness. The first factor contains seven items capturing feelings of connectedness (range $7-21$; reliability $=0.95$ ). The second factor consists of four items that acknowledge feelings of isolation (range $4^{-12}$; reliability $=0.93$ ). The exact items of these two scales and their factor loadings are shown in Table 3 .

Control variables. In this study, we controlled for demographics, cognitive functioning, self-related health, social network characteristics and offline social interactions because prior work has suggested that these variables may influence perceived support (Berkman et al. 2000; Finch and Vega 2003; Seeman et al. 2001) and loneliness (Cornwell and Waite 2009; Tilvis et al. 2004).

Demographics: Demographic variables included age, gender $(1=$ female $)$, years of education $(0-17$ years $)$, marital status $(1=$ married $)$, race and ethnicity $(1=$ non-Hispanic White), wealth quartiles $(\mathrm{o}=$ lowest and $4=$ highest), income quartiles $(\mathrm{o}=$ lowest and 4 =highest $)$ and employment status $(1=$ employed $)$.

Cognitive functioning: Cognitive functioning was assessed with ten-word immediate and delayed recall tests of memory, a serial $7 \mathrm{~s}$ subtraction test of working memory, and counting backwards to assess attention and processing speed. Composite scores using all the items created a measure of cognitive functioning, which could range from o to 27. Higher scores represented better cognitive functioning. Those who were unable to answer for themselves due to physical or cognitive limitations may have been represented 
by a proxy respondent. However, because proxy respondents did not answer the cognitive battery on behalf of the respondents, those represented by a proxy were not included in the analyses.

Self-rated health: Self-rated health was measured using one question: 'Would you say your health is excellent, very good, good, fair, or poor?' The response scale ranged from 1 (poor) to 5 (excellent).

Number of close contacts: Number of close contacts was the sum of the number of three types of close social ties, namely children, other immediate family, and friends. To assess number of close ties, respondents were asked: 'How many of your [children/family members/friends] would you say you have a close relationship with?' Respondents who did not have any living children, other immediate family or friends were assigned o for that particular relational type(s). The composite measure of number of close contacts was created by summing the number of close children, other family, and friends. The 13 ( 2 per cent) responses above 30 were recoded to 30 to avoid influential observations and sparsity.

Frequency of in-person and phone interactions with social ties: Frequency of offline interactions, including meeting up and speaking on the phone, were asked in loops in reference to three relational types, namely children, other immediate family (such as brothers, sisters, parents, cousins or grandchildren) and friends. The response scale ranged from 1 (less than once a year or never) to 6 (three or more times a week). Those who had no living children, other immediate family or friends were assigned 1 for in-person or phone interactions with that particular social tie(s). Composite measures of frequency of meeting up and speaking on the phone with social ties were created by summing in-person and phone interactions with three types of ties, respectively. The composite measures could range from 3 to 18 .

\section{Data analysis}

We first examined bivariate differences between SNS users and non-users. We then conducted ordinary least-squares (OLS) regression analyses to investigate the relationships between SNS use and social wellbeing outcomes. All the regression models were adjusted for age, gender, race/ethnicity, education, income, wealth, marital status, work status, cognitive functioning, self-rated health, number of close contacts, and frequency of inperson and phone interactions with social ties. The models were weighted using 2012 HRS sampling weights. We conducted the analyses in SAS 9.3 using the appropriate survey procedures to generate estimates and standard errors corrected for the complex sample design. We created an interaction term between age (centred at age 52) and SNS use, and performed 
regression analyses to examine whether and how the associations between SNS use and social wellbeing outcomes differ by age in the older population.

\section{Results}

Table 2 shows the descriptive statistics of all variables by SNS use. SNS users are more likely to be younger, more educated, female, non-Hispanic White, employed, and to have higher income, better cognitive functioning, higher self-rated health, a lower number of close contacts, perceived greater support from friends, lower feelings of isolation and higher feelings of connectedness than non-users.

\section{SNS use and perceived support}

To examine the question of the relevance of SNS use and perceived support from different relationships, OLS regression analysis was performed. The first set of hypotheses, predicting that SNS use is not significantly associated with perceived support from children ( $\left.\mathrm{H}_{1 \mathrm{a}}\right)$ or other family $\left(\mathrm{H}_{1} \mathrm{~b}\right)$, is partially supported. Models 1 and 3 in Table 4 show that SNS use is not significantly associated with perceived support from other immediate family ( $\beta=0.05 ; p=0.07)$, supporting $\mathrm{H}_{1} \mathrm{~b}$. However, contrary to our expectation (H1a), SNS use is significantly related to increased perceived support from children $(\beta=0.08 ; p<0.05)$. Further, Model 5 in Table 4 suggests that SNS use is significantly and positively associated with perceived support from friends $(\beta=0.13 ; p<0.001)$, above and beyond the influence of demographics, cognitive functioning and health, size of close networks, and offline interactions with social ties, supporting H2. Overall, results show that SNS use is positively related to non-kin-related support (i.e. perceived support from friends) and one type of kin-related support (i.e. perceived support from children).

\section{SNS use and dimensions of loneliness}

Turning to the question of how SNS use relates to dimensions of loneliness $\left(\mathrm{H}_{3}\right.$ and $\left.\mathrm{H}_{4}\right)$, as Models 1 and 3 in Table 5 show, SNS use is positively and significantly associated with feelings of connectedness $(\beta=0.10$; $p<0.001)$, but is not significantly predictive of feelings of isolation ( $\beta=-0.05 ; p=0.08)$, supporting $\mathrm{H}_{3}$ and $\mathrm{H}_{4}$. Results suggest that SNS use is positively associated with non-kin-related loneliness (i.e. feelings of connectedness), but is not significantly related to kin-related loneliness (i.e. feelings of isolation). 
T А В L E 4. Ordinary least-squares regression analysis: predicting perceived support from children, other family and friends

\begin{tabular}{|c|c|c|c|c|c|c|c|c|c|c|c|c|}
\hline & \multicolumn{4}{|c|}{ Support from children } & \multicolumn{4}{|c|}{ Support from family } & \multicolumn{4}{|c|}{ Support from friends } \\
\hline & \multicolumn{2}{|c|}{ Model 1} & \multicolumn{2}{|c|}{ Model 2} & \multicolumn{2}{|c|}{ Model 3} & \multicolumn{2}{|c|}{ Model $_{4}$} & \multicolumn{2}{|c|}{ Model 5} & \multicolumn{2}{|c|}{ Model 6} \\
\hline & $B(\mathrm{SE})$ & $\beta$ & $B(\mathrm{SE})$ & $\beta$ & $B(\mathrm{SE})$ & $\beta$ & $B(\mathrm{SE})$ & $\beta$ & $B(\mathrm{SE})$ & $\beta$ & $B(\mathrm{SE})$ & $\beta$ \\
\hline Intercept & $\begin{array}{l}3.5^{6 * * *} \\
(0.47)\end{array}$ & 0.00 & $\begin{array}{l}3 \cdot 47^{* * *} \\
(0.47)\end{array}$ & 0.00 & $\begin{array}{l}3.3^{6 * * *} \\
(0.57)\end{array}$ & 0.00 & $\begin{array}{l}3.25^{* * *} \\
(0.54)\end{array}$ & 0.00 & $\begin{array}{l}5.28 * * * \\
(0.38)\end{array}$ & 0.00 & $\begin{array}{l}5.27^{* * *} \\
(0.38)\end{array}$ & 0.00 \\
\hline Age & $\begin{array}{l}\text { o.o6*** } \\
\text { (o.o1) }\end{array}$ & $0.3^{0}$ & $\begin{array}{l}0.07^{* * *} \\
(0.01)\end{array}$ & 0.34 & $\begin{array}{c}0.03^{*} \\
(0.01)\end{array}$ & 0.10 & $\begin{array}{l}0.03^{* *} \\
(0.01)\end{array}$ & 0.13 & $\begin{array}{l}-0.01 \\
(0.01)\end{array}$ & -0.03 & $\begin{array}{l}-0.01 \\
(0.01)\end{array}$ & -0.02 \\
\hline Years of education & $\begin{array}{l}-0.03 \\
(0.03)\end{array}$ & -0.04 & $\begin{array}{l}-0.03 \\
(0.03)\end{array}$ & -0.03 & $\begin{array}{l}0.06 * \\
(0.03)\end{array}$ & 0.06 & $\begin{array}{l}0.06 * \\
(0.03)\end{array}$ & 0.06 & $\begin{array}{c}0.02 \\
(0.03)\end{array}$ & 0.02 & $\begin{array}{c}0.02 \\
(0.03)\end{array}$ & 0.02 \\
\hline Female & $\begin{array}{l}0.21 \\
(0.11)\end{array}$ & 0.05 & $\begin{array}{c}0.17 \\
(0.11)\end{array}$ & 0.04 & $\begin{array}{l}0.42^{* *} \\
(0.14)\end{array}$ & 0.08 & $\begin{array}{l}0.4 \mathrm{O}^{* *} \\
(0.14)\end{array}$ & 0.08 & $\begin{array}{l}0.66^{* * *} \\
(0.13)\end{array}$ & 0.15 & $\begin{array}{l}0.66^{* * *} \\
(0.13)\end{array}$ & 0.15 \\
\hline Married & $\begin{array}{l}0.5^{0^{* *}} \\
(0.17)\end{array}$ & 0.11 & $\begin{array}{l}0.47^{* *} \\
(0.17)\end{array}$ & 0.10 & $\begin{array}{l}-0.04 \\
(0.23)\end{array}$ & -0.01 & $\begin{array}{l}-0.04 \\
(0.23)\end{array}$ & -0.01 & $\begin{array}{c}-1.12^{* * *} \\
(0.17)\end{array}$ & -0.23 & $\begin{array}{l}-1.12^{* * * *} \\
(0.17)\end{array}$ & -0.23 \\
\hline Non-Hispanic White & $\begin{array}{l}0.3^{6} \\
(0.19)\end{array}$ & 0.06 & $\begin{array}{c}0.3^{2} \\
(0.20)\end{array}$ & 0.05 & $\begin{array}{l}-0.43 \\
(0.24)\end{array}$ & -0.06 & $\begin{array}{c}-0.4^{6} \\
(26)\end{array}$ & -0.06 & $\begin{array}{c}0.06 \\
(0.17)\end{array}$ & 0.01 & $\begin{array}{c}0.05 \\
(0.17)\end{array}$ & 0.01 \\
\hline Income & $\begin{array}{l}0.09^{*} \\
(0.04)\end{array}$ & 0.06 & $\begin{array}{c}0.09^{*} \\
(0.04)\end{array}$ & 0.06 & $\begin{array}{l}-0.22^{* * *} \\
(0.05)\end{array}$ & -0.12 & $\begin{array}{l}-0.22^{* * *} \\
(0.05)\end{array}$ & -0.12 & $\begin{array}{l}0.15^{* * *} \\
(0.04)\end{array}$ & o.og & $\begin{array}{l}0.15^{* * *} \\
(0.04)\end{array}$ & 0.09 \\
\hline Wealth & $\begin{array}{l}-0.01 \\
(0.06)\end{array}$ & -0.01 & $\begin{array}{l}-0.01 \\
(0.06)\end{array}$ & -0.01 & $\begin{array}{l}-0.13 \\
(0.07)\end{array}$ & -0.07 & $\begin{array}{l}-0.13 \\
(0.07)\end{array}$ & -0.07 & $\begin{array}{c}0.07 \\
(0.05)\end{array}$ & 0.04 & $\begin{array}{c}0.07 \\
(0.05)\end{array}$ & 0.04 \\
\hline Employed & $\begin{array}{l}0.24^{*} \\
(0.11)\end{array}$ & 0.06 & $\begin{array}{c}0.24^{*} \\
(0.11)\end{array}$ & o.o6 & $\begin{array}{l}0.4^{* *} \\
(0.14)\end{array}$ & 0.08 & $\begin{array}{l}0.4^{* *} \\
(0.14)\end{array}$ & 0.08 & $\begin{array}{l}-0.05 \\
(0.22)\end{array}$ & -0.01 & $\begin{array}{c}-0.05 \\
(0.22)\end{array}$ & -0.01 \\
\hline Cognitive functioning & $\begin{array}{l}0.00 \\
(0.02)\end{array}$ & 0.00 & $\begin{array}{l}0.00 \\
(0.02)\end{array}$ & 0.00 & $\begin{array}{c}0.05 \\
(0.03)\end{array}$ & 0.08 & $\begin{array}{c}0.05 \\
(0.03)\end{array}$ & 0.08 & $\begin{array}{c}0.00 \\
(0.01)\end{array}$ & o.oo & $\begin{array}{c}0.00 \\
(0.01)\end{array}$ & 0.00 \\
\hline Self-rated health & $\begin{array}{l}0.19^{* * *} \\
(0.05)\end{array}$ & 0.10 & $\begin{array}{l}0.19^{* * *} \\
(0.05)\end{array}$ & 0.10 & $\begin{array}{l}0.04 \\
(0.06)\end{array}$ & 0.02 & $\begin{array}{c}0.04 \\
(0.06)\end{array}$ & 0.02 & $\begin{array}{l}0.20^{* * * *} \\
(0.06)\end{array}$ & 0.10 & $\begin{array}{l}0.20^{* * *} \\
(0.06)\end{array}$ & 0.10 \\
\hline Number of close contacts & $\begin{array}{l}0.08 * * * \\
(0.01)\end{array}$ & 0.24 & $\begin{array}{l}0.08 * * * \\
(0.01)\end{array}$ & 0.24 & $\begin{array}{l}0.08 * * * \\
(0.02)\end{array}$ & 0.19 & $\begin{array}{l}0.08 * * * \\
(0.02)\end{array}$ & 0.19 & $\begin{array}{l}0.09^{* * * *} \\
(0.01)\end{array}$ & 0.25 & $\begin{array}{l}\mathrm{O}^{\circ} 09^{* * *} \\
(\mathrm{o.01})\end{array}$ & 0.25 \\
\hline Meeting & $\begin{array}{l}\text { o.0o } \\
(0.02)\end{array}$ & 0.00 & $\begin{array}{l}0.00 \\
(0.02)\end{array}$ & 0.00 & $\begin{array}{l}0.03 \\
(0.03)\end{array}$ & 0.04 & $\begin{array}{l}\text { o.03 } \\
(0.03)\end{array}$ & 0.03 & $\begin{array}{c}0.04 \\
(0.02)\end{array}$ & 0.05 & $\begin{array}{c}0.04 \\
(0.02)\end{array}$ & 0.05 \\
\hline Speaking & $\begin{array}{l}0.21^{* * * *} \\
(0.03)\end{array}$ & 0.24 & $\begin{array}{l}0.21 * * * \\
(0.03)\end{array}$ & 0.24 & $\begin{array}{l}0.21 * * * \\
(0.03)\end{array}$ & 0.21 & $\begin{array}{l}0.21^{* * *} \\
(0.03)\end{array}$ & 0.22 & $\begin{array}{l}0.10^{* * * *} \\
(0.02)\end{array}$ & 0.12 & $\begin{array}{l}0.10^{* * * *} \\
(0.02)\end{array}$ & 0.12 \\
\hline
\end{tabular}


SNS

Age $\times$ SNS

$R^{2}(\%)$

$\mathrm{N}$

$4^{10}$

Notes: SE: standard error. SNS: social network site. All models are survey-adjusted.

Significance levels: $* p<0.05$, $* * p<0.01, * * * p<0.001$.

\begin{tabular}{|c|c|c|c|c|c|c|c|c|c|}
\hline $\begin{array}{l}0.84^{* * * *} \\
(0.20)\end{array}$ & 0.19 & $\begin{array}{c}0.28 \\
(0.15)\end{array}$ & 0.05 & $\begin{array}{c}0.60^{*} \\
(0.28)\end{array}$ & 0.11 & $\begin{array}{l}0.60^{* * * *} \\
(0.14)\end{array}$ & 0.13 & $\begin{array}{c}0.61^{*} \\
(0.25)\end{array}$ & 0.13 \\
\hline $\begin{array}{l}-0.04^{* * * *} \\
(0.01)\end{array}$ & -0.14 & & & $\begin{array}{c}-0.03 \\
(0.01)\end{array}$ & -0.07 & & & $\begin{array}{c}0.00 \\
(0.01)\end{array}$ & 0.00 \\
\hline 25.86 & & $17 \cdot 32$ & & $17 \cdot 5^{1}$ & & 19.62 & & 19.62 & \\
\hline 110 & & $45^{6}$ & & $45^{6}$ & & $4^{60}$ & & $4^{60}$ & \\
\hline
\end{tabular}

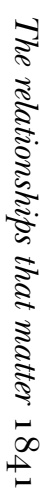


T A в L E 5. Ordinary least-squares regression analysis: predicting feelings of isolation and connectedness

\begin{tabular}{|c|c|c|c|c|c|c|c|c|}
\hline & \multicolumn{4}{|c|}{ Feelings of isolation } & \multicolumn{4}{|c|}{ Feelings of connectedness } \\
\hline & \multicolumn{2}{|l|}{ Model 1} & \multicolumn{2}{|l|}{ Model 2} & \multicolumn{2}{|l|}{ Model 3} & \multicolumn{2}{|l|}{ Model 4} \\
\hline & $B(\mathrm{SE})$ & $\beta$ & $B(\mathrm{SE})$ & $\beta$ & $B(\mathrm{SE})$ & $\beta$ & $B(\mathrm{SE})$ & $\beta$ \\
\hline Intercept & $9.08 * * *(0.48)$ & 0.00 & $9.10^{* * *}(0.48)$ & 0.00 & $8.3^{6 * * *}(0.65)$ & 0.00 & $8.53^{* * *}(0.64)$ & 0.00 \\
\hline Age & $-0.04 * * *(0.01)$ & -0.18 & $-0.04^{* * *}(0.01)$ & -0.19 & $0.03 * * *(0.01)$ & 0.11 & $0.02 *(0.01)$ & 0.07 \\
\hline Years of education & $0.07^{*}(0.03)$ & 0.08 & $0.07 *(0.03)$ & 0.08 & $-0.04(0.04)$ & -0.03 & $-0.04(0.04)$ & -0.03 \\
\hline Female & $-0.32^{* *}(0.11)$ & -0.07 & $-0.3^{2 * *}(0.11)$ & -0.07 & $0.43^{* *}(0.16)$ & 0.07 & $0.47^{* *}(0.16)$ & 0.08 \\
\hline Married & $-1.31 * * *(0.11)$ & -0.29 & $-1.31^{* * *}(0.11)$ & -0.29 & $-0.12(0.17)$ & -0.02 & $-0.12(0.17)$ & -0.02 \\
\hline Non-Hispanic White & $0.59^{* * *}(0.13)$ & 0.10 & $0.60 * * *(0.13)$ & 0.10 & $0.70^{* *}(0.24)$ & 0.08 & $0.75^{* *}(0.23)$ & 0.08 \\
\hline Income & $0.05(0.03)$ & 0.03 & $0.05(0.03)$ & 0.03 & $0.21 * * *(0.05)$ & 0.09 & $0.20^{* * *}(0.05)$ & 0.09 \\
\hline Wealth & $-0.12^{* *}(0.04)$ & -0.07 & $-0.12^{* *}(0.04)$ & -0.07 & $0.22 * * *(0.06)$ & 0.09 & $0.22 * * *(0.06)$ & 0.09 \\
\hline Employed & $-0.42^{* *}(0.13)$ & -0.10 & $-0.42^{* *}(0.13)$ & -0.10 & $-0.03(0.15)$ & o.oO & $-0.03(0.14)$ & 0.00 \\
\hline Cognitive functioning & $-0.10^{* * *}(0.02)$ & -0.19 & $-0.10^{* * *}(0.02)$ & -0.19 & $0.09^{* * *}(0.01)$ & 0.13 & $0.09 * * *(0.01)$ & 0.12 \\
\hline Self-rated health & $-0.29^{* * *}(0.05)$ & -0.14 & $-0.29 * * *(0.05)$ & -0.14 & $0.65 * * *(0.07)$ & 0.22 & $0.65 * * *(0.07)$ & 0.22 \\
\hline Number of close contacts & $-0.05^{* * *}(0.01)$ & -0.15 & $-0.05^{* * *}(0.01)$ & -0.15 & $0.15 * * *(0.01)$ & 0.29 & $0.15^{* * *}(0.01)$ & 0.29 \\
\hline Meeting & $-0.14^{* * *}(0.02)$ & -0.18 & $-0.13^{* * *}(0.02)$ & -0.18 & $0.07(0.04)$ & 0.06 & $0.07 *(0.04)$ & 0.07 \\
\hline Speaking & $0.14^{* * *}(0.02)$ & 0.18 & $0.14^{* * *}(0.02)$ & 0.18 & $0.11 * *(0.03)$ & 0.09 & $0.11 * *(0.03)$ & 0.09 \\
\hline SNS & $-0.21(0.12)$ & -0.05 & $-0.25(0.18)$ & -0.06 & $0.69 * * *(0.12)$ & 0.10 & $0.11(0.18)$ & 0.02 \\
\hline Age $\times$ SNS & & & $0.00(0.01)$ & 0.01 & & & $0.05 * * *(0.01)$ & 0.10 \\
\hline$R^{2}(\%)$ & 25.08 & & 25.09 & & 27.92 & & 28.29 & \\
\hline $\mathrm{N}$ & $4^{6} 3$ & & 463 & & 463 & & 463 & \\
\hline
\end{tabular}

Notes: SE: standard error. SNS: social network site. All models are survey-adjusted.

Significance levels: $* p<0.05, * * p<0.01, * * * p<0.001$. 


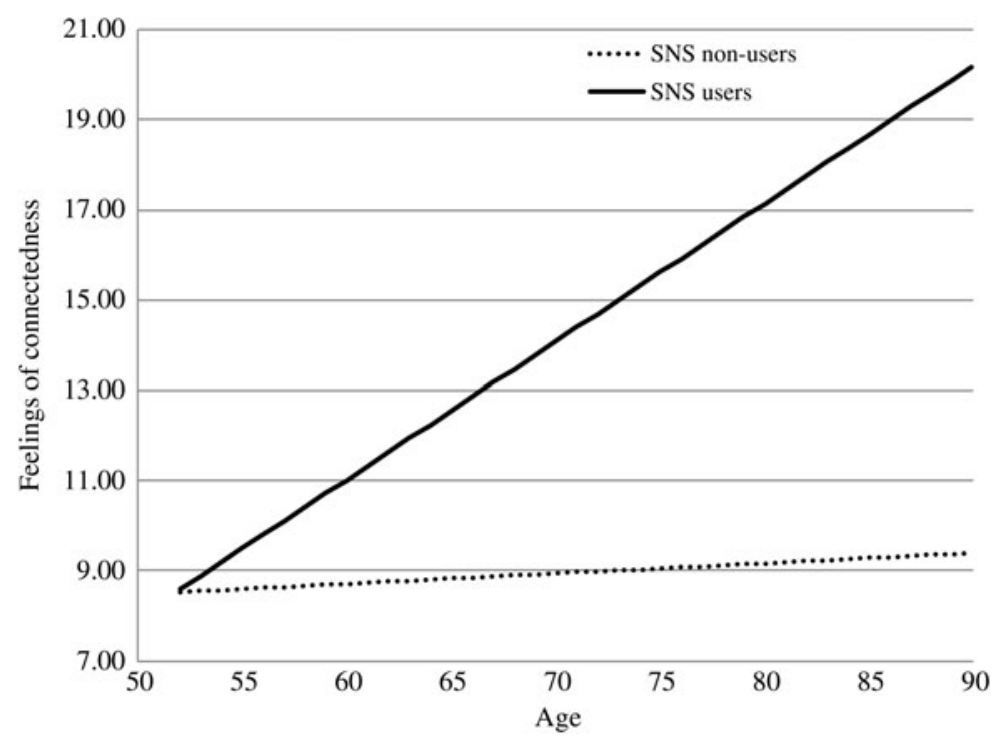

Figure 1. Illustration of the relationship between the interaction of age and social network site (SNS) use and feelings of connectedness.

\section{Interaction of age, SNS use and social wellbeing}

Next, we examine whether and how age and SNS use interactively relate to non-kin- and kin-related social wellbeing ( $\mathrm{RQ}_{1}$ and $\mathrm{RQ}_{2}$ ). For non-kinrelated social wellbeing, Age $\times$ SNS is only positively associated with feelings of connectedness $(\beta=0.10 ; p<0.001 ;$ see Table 5 , Model 4$)$. For a better illustration, the significant result is plotted in Figure 1. The solid line represents SNS users, and the dashed line represents non-users. Figure 1 shows that SNS users perceive higher feelings of connectedness as they age, but non-users' feelings of connectedness remain relatively flat with age, suggesting that SNS use contributes to feelings of connectedness to a greater extent as people age.

For kin-related social wellbeing, Age $\times$ SNS only predicts decreased perceived support from children $(\beta=-0.14 ; p<0.001$; see Table 4 , Model 2). The interaction result is plotted in Figure 2, following the same rationale of presentation employed in the previous figure. As one can see, SNS users perceive higher support from children than non-users in their fifties and sixties but non-users perceive higher support from children than SNS users beyond the mid-seventies. As earlier reported findings indicate that SNS use is positively linked to perceived support from children, the significant interaction finding further reveals that this positive relationship is primarily driven by the younger-old adults in this population. 


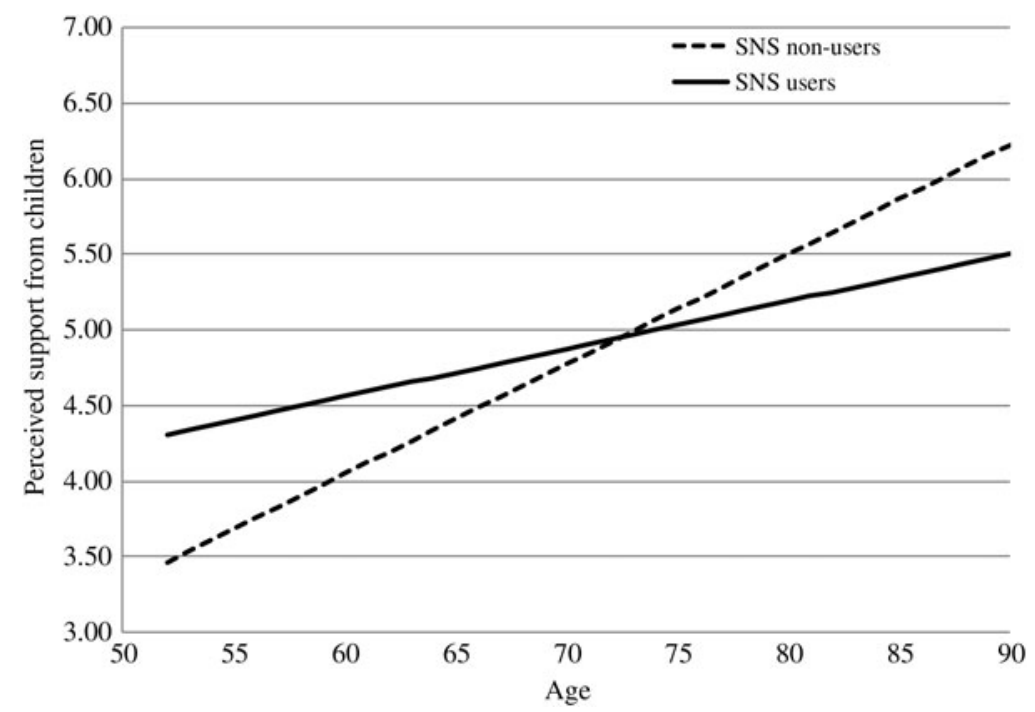

Figure 2. Illustration of the relationship between the interaction of age and social network site (SNS) use and perceived support from children.

\section{Discussion}

In this study, we employ a representative sample of Americans over age $5^{\mathrm{o}}$ to investigate the relationships between SNS use and social wellbeing outcomes, broadly defined as perceived social support and loneliness. In particular, this study contributes to our understanding of social wellbeing outcomes associated with SNS use by (a) identifying how SNS use is differentially associated with types of social wellbeing outcomes - one is associated with kin relations and the other is linked to non-kin relations; and (b) exploring whether and how the associations between SNS use and types of social wellbeing outcomes vary by age. In the following section, we discuss the theoretical implications of our findings.

First, our findings suggest that SNSs may be well-suited for enhancing middle-aged and older adults' ability to receive social benefits associated with non-kin relations, as we found that SNS use contributes to non-kinrelated social wellbeing - perceived support from friends and feelings of connectedness - above and beyond the influence of demographics, cognitive and perceived health, size of kin networks and offline interactions with social ties in this population. The positive relationships are consistent with prior work using general adult samples with longitudinal designs, which found that Facebook use increases perceived closeness with nonfamily members (Burke and Kraut 2014). While existing literature suggests 
that the initial motivation for older adults to adopt SNSs is to connect with kin ties (e.g. children and other relatives), SNSs' technical and social options may help these older users expand their networks by connecting them to non-kin ties (e.g. new and old acquaintances) (Khvorostianov, Elias and Nimrod 2012; Quinn 2013). The sense of having a social network to connect with or belonging to a group of others through SNS use may contribute to users' feelings of connectedness. Moreover, because SNSs are likely to be the primary venue for older adults to keep up with and exchange messages with these non-kin ties, activities on SNSs may contribute to increased perceptions of support from friends.

We found that the contribution of SNS use to feelings of connectedness increases as people become older, suggesting that SNS use may become an increasingly important source of feelings of connectedness over time for older adults. Scholarship suggests that older adults often cultivate new social connections to adapt to involuntary loss of social roles and contacts in later life (e.g. Atchley 1989), which provides one explanation for this observed relationship. As older adults have decreased social engagement with age due to involuntary reasons, such as retirement and health declines, opportunities to interact with non-kin relations may reduce with age accordingly. In that regard, SNSs may become one of the few reliable and accessible mechanisms through which older adults can connect with non-kin relations and thus cultivate feelings of connectedness as they age.

As the contribution of SNS use to feelings of connectedness increases with age, one might expect that SNS use would also enhance perceived support from friends to a greater extent with age. However, we found that SNS use's relationship to perceived support from friends does not significantly differ by age. One explanation for the results is that once connected with non-kin ties, older adults may not wish to rekindle more engaged relationships or engage in reciprocal interactions on SNSs (Quinn 2013), as prior work suggests that individuals voluntarily withdraw from weak relationships in order to focus on maintaining strong relations with age (Carstensen 1993). Another possibility is that because the older cohort tends to have more concerns regarding internet use, such as privacy and trust (Gibson et al. 2010; Xie et al. 2012), reluctance to self-promote (Lehtinen, Näsänen and Sarvas 2009), and a tendency to use the internet more for consumption than sharing information (Bloch and Bruce 2011), these older individuals may also be less likely to engage in public forms of interactions on SNSs (such as commenting or posting), and in turn, miss the opportunities to receive more support from friends. Past research has shown that Facebook users who use the system to ask for help from their networks report higher social capital perceptions (Ellison et al. 2014), but older adults may be less comfortable engaging in these kinds of activities. 
Together, these findings suggest that SNS use may enhance middle-aged and older adults' social wellbeing, associated with non-kin relations who do not frequently communicate via other channels. As older adults often use SNSs to locate past acquaintances or even make new ones (Khvorostianov, Elias and Nimrod 2012; Quinn 2013), these extended network connections may contribute to feelings of connectedness and increased perceptions of support from friends. Importantly, as older adults tend to have fewer social resources due to life transitions with age, our results suggest that SNS use may become an increasingly important source of feelings of connectedness in the later lifespan. These findings seem to be in line with the involuntary loss perspective, which argues that while common life transitions (e.g. retirement and widowhood) connote loss and isolation, older adults often develop new social connections (often weak ties) to compensate for the loss (Cornwell and Laumann 2015). In this sense, SNS use may be one of the ways in which older adults cultivate dormant or even new social connections to adapt to later-life challenges.

Second, consistent with expectations, we found that SNS use is not significantly related to perceived support from most family (other than children) and feelings of isolation. It may be that because older adults use multiple channels to interact with other family members, such as siblings and cousins, SNS use may have less impact on perceived support from these relationships and feelings of distance from intimate others. However, contrary to our expectations, SNS use does predict increased perceived support from children, although this relationship is weaker than the relationship between SNS use and perceived support from friends. Why might this be? The significant effect of the interaction between age and SNS use on perceived support from children provides some insight into this unexpected result. That is, the positive relationship between SNS use and increased support from children is primarily driven by the youngerold adults in the older population. Indeed, we know that many teens and young adults have integrated SNS use into their daily lives (boyd 2007), and that younger-old adults are more adaptive and competent in technology use (Lindley, Harper and Sellen 2oog). Perhaps SNSs are being used by these younger-old users in our sample to connect with their young adult children. There is some empirical support for this interpretation. For example, in an interview study with adults aged $55^{-64}$, one participant said, 'I got involved in Facebook because it was the best way to stay in touch with my 25-year-old daughter. She tends to communicate in short 'bites', and emailing or phone calls wasn't really working' (Goode 2011: 6). As SNSs may facilitate interaction between younger-old adults and their children, use of these tools may enhance older adults' perceptions of support from children. In contrast, as those who are older in the older population 
may be less adaptive to technology use (Lindley, Harper and Sellen 2oog), even after they adopt SNSs, they are more likely to stick with tried and true communication practices, such as phone or in-person communication, to connect with their children. As a result, SNSs are less likely to become the primary platform for these older adults to interact with their children, and thus play a lesser role in enhancing their perception of support from children.

Taken together, these patterns of results are largely consistent with previous research which shows that SNS use has little impact on perceived closeness with family members (Burke and Kraut 2014), perhaps because other channels are used in addition to SNSs. However, we may see some of these patterns change over time as communication preferences and habits evolve. For the next generation, SNSs may become a primary communication channel through which younger-old adults interact with their children, contributing to increased perception of support from children. One important task for future research will be to investigate how older adults' communication practices with various social ties evolve over time, and the extent to which SNS-mediated communication practices contribute to kin-related social wellbeing beyond the use of other channels to communicate with these ties.

Several potential limitations of this study should be noted, as they also suggest opportunities for future research. First, because only cross-sectional data were used, the results of this study indicate associations between measures that should not be interpreted as causal relationships. Longitudinal research is needed to determine the directionality of these relationships. Further, research using longitudinal approaches will advance our understanding of whether and how the role of SNSs in facilitating older adults' interactions with various social contacts evolves over time. Another possible limitation of this study is that SNS use was assessed by a simple dichotomous measure. SNSs are better understood to be a toolkit - a collection of features that allow users to engage in a wide variety of activities (Smock et al. 2011 ) - as opposed to a single 'tool' with one uniform activity pattern; similarly, different outcomes are associated with different usage patterns. For example, prior work shows that the effect of Facebook use on perceived closeness to social relationships is stronger for activities that involve greater effort, such as posting messages or comments, than for actions requiring little effort, such as 'liking' a post (Burke and Kraut 2014). Thus, one of the most important steps in future research will be to incorporate more fine-grained measures to capture older adults' activities on SNSs, which, in turn, would futher our understanding of the mechanisms by which SNS use contributes to social wellbeing across different later-life stages. 
A third limitation is the study's focus on older adults in the USA, an individualistic society that values independence and a wider range of nonfamilial bonds. As a result of this focus, it is unclear whether the patterns of results can be generalised to collectivistic societies that emphasise interdependence and family connectedness. For example, while we found that SNS use is positively related to perceived support from children, this finding may not be generalised to older adults in collectivistic societies. As norms of filial responsibilities are more salient in collectivistic societies, such as eastern Asia and Mediterranean countries, parents are more likely to live with or live close to their children in these societies (Dykstra and Fokkema 201 1; Sugisawa et al. 2002). This, in turn, may decrease the reliance on SNSs in facilitating such parents' interactions with children and the possibility of receiving support from children via SNS interactions. Considering these possible cultural differences, future research should employ crosscultural approaches to investigate whether and how SNS use and its influence on social wellbeing differ across nations and/or cultures.

Despite these limitations, this study is an important first step in investigating the relationships between SNS use and social wellbeing using a nationally representative sample of middle-aged and older adults in the USA. Our findings suggest that SNSs may be well-suited for enhancing older adults' ability to receive social benefits associated with non-kin relations, such as increased perceptions of support from friends and feelings of connectedness to a network of friendships. In particular, SNSs may be especially beneficial for older adults with regard to feelings of connectedness during the ageing process. For kin-related social wellbeing, while SNS use is not significantly related to perceived support from family and feelings of isolation, SNS use contributes to perceived support from children, suggesting that the communication practices between younger-old adults and their children may be evolving. We are hopeful that this study furthers our understanding of SNS use and its implications for social wellbeing vis-à-vis different relation types, while revealing how these associations differ across later stages of the lifespan.

\section{Acknowledgements}

This work was supported by a grant from the National Academies Keck Futures Initiative. The Health and Retirement Study is conducted by the Institute for Social Research at the University of Michigan, with funding from the National Institute on Aging (Uo1 AGoo9740). The authors certify that they have no affiliations with or involvement in any organisation or entity with any financial or nonfinancial interest in the subject matter or materials discussed in this paper. Ethical approval was not required. 


\section{NOTE}

1 Reliability estimates for ordinal items are reported based on Mislevy and Bock (1990).

\section{References}

Ahn, D. and Shin, D.-H. 2013. Is the social use of media for seeking connectedness or for avoiding social isolation? Mechanisms underlying media use and subjective well-being. Computers in Human Behavior, 29, 6, 2453-62.

Atchley, R. C. 1989. A continuity theory of normal aging. The Gerontologist, 29, 2, 183-90.

Bakshy, E., Rosenn, I., Marlow, C. and Adamic, L. A. 2012. The role of social networks in information diffusion. In Rabinovich, M. and Staab, S.(eds), Proceedings of the 2 I st International Conference on World Wide Web. ACM, New York, 519-28.

Bell, C., Fausset, C., Farmer, S., Nguyen, J., Harley, L. and Fain, W. B. 2013. Examining social media use among older adults. In Hotho, A.(ed.), Proceedings

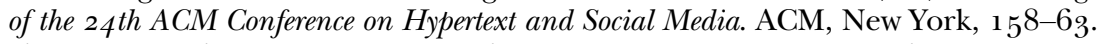

Berkman, L. F., Glass, T., Brissette, I. and Seeman, T. E. 200o. From social integration to health: Durkheim in the new millennium. Social Science $\mathcal{E}$ Medicine, 51, 6, 843-57.

Bloch, N. and Bruce, B. C. 2011 . Older adults and the new public sphere. In Fisher, K. E. and Mai, J-E.(eds), Proceedings of the 20 I I iConference. ACM, New York, 1-7.

boyd, d. 2007. Why youth social network sites: the role of networked publics in teenage social life. In Buckingham, D. (ed.), Youth, Identity, and Digital Media. MIT Press, Cambridge, Massachusetts, $119-42$.

Brandtzæg, P. B., Lüders, M. and Skjetne, J. H. 2010. Too many Facebook 'friends'? Content sharing and sociability versus the need for privacy in social network sites. International Journal of Human-Computer Interaction, 26, 11 / 1 2, 1006-30.

Burke, M., Adamic, L. A. and Marciniak, K. 201 3. Families on Facebook. In Ellison, N.B., Hogan, B., Resnick, P. and Soboroff, I. (eds), Proceedings of the 7 th International AAAI Conference on Weblogs and Social Media. The AAAI Press, Palo Alto, California, 41-50.

Burke, M. and Kraut, R. E. 2014. Growing closer on Facebook: changes in tie strength through social network site use. In Schmidt, A. and Grossman, T. (eds), Proceedings of the SIGCHI Conference on Human Factors in Computing Systems. ACM, New York, $4187-96$.

Burke, M., Marlow, C. and Lento, T. 2010. Social network activity and social well-being. In Fitzpatrick, G., Hudson, S., Edwards, K. and Rodden, T. (eds), Proceedings of the SIGCHI Conference on Human Factors in Computing Systems. ACM, New York, 1909-12.

Carstensen, L. L. 1993. Motivation for social contact across the life span: a theory of socioemotional selectivity. In Jacobs, J. (ed.), Nebraska Symposium on Motivation. University of Nebraska Press, Lincoln, Nebraska, 209-54.

Charness, N. and Boot, W. R. 20o9. Aging and information technology use: potential and barriers. Current Directions in Psychological Science, 18, 5, 253-58.

Cohen, S. 2004. Social relationships and health. American Psychologist, 59, 8, 676-84.

Conway, F., Magai, C., Jones, S., Fiori, K. and Gillespie, M. 2013. A six-year follow-up study of social network changes among African-American, Caribbean, and USborn Caucasian urban older adults. International Journal of Aging and Human Development, $\mathbf{7 6}, \mathbf{1}, \mathbf{1}-\mathbf{2 7}$.

Cornwell, B. and Laumann, E. O. 2015. The health benefits of network growth: new evidence from a national survey of older adults. Social Science $\mathcal{E}$ Medicine, 125, 94-106. 
Cornwell, B., Laumann, E. O. and Schumm, L. P. 2008. The social connectedness of older adults: a national profile. American Sociological Review, 73, 2, $185^{-203 .}$

Cornwell, E.Y. and Waite, L.J. 2009. Social disconnectedness, perceived isolation, and health among older adults. Journal of Health and Social Behavior, 5o, 1, 31-48.

Cotten, S. R., Anderson, W. A. and McCullough, B. M. 2013. Impact of Internet use on loneliness and contact with others among older adults: cross-sectional analysis. Journal of Medical Internet Research, 15, 2, e39.

Dickinson, A. and Hill, R. L. 2007. Keeping in touch: talking to older people about computers and communication. Educational Gerontology, 33, 8, 613-30.

Donath, J. 2007. Signals in social supernets. Journal of Computer-mediated Communication, 13, $1,23^{1-} 5^{1}$.

Duggan, M., Ellison, N. B., Lampe, C., Lenhart, A. and Madden, M. 2015. Social Media Update 2014. Pew Internet \& American Life Project, Washington DC. Available online at http://www.pewinternet.org/2015/o1/og/social-mediaupdate-2014/ [Accessed 26 March 2015].

Dykstra, P. A. and Fokkema, T. 2011 . Relationships between parents and their adult children: a West European typology of late-life families. Ageing $\mathcal{G}$ Society, 31, 4, $545^{-69 .}$

Ellison, N. B. and boyd, d. 2013. Sociality through social network sites. In Dutton, W. H. (ed.), The Oxford Handbook of Internet Studies. Oxford University Press, Oxford, $15^{1-72 .}$

Ellison, N. B., Steinfield, C. and Lampe, C. 2007. The benefits of Facebook 'friends': social capital and college students' use of online social network sites. Journal of Computer-mediated Communication, 12, 4, 1143-68.

Ellison, N. B., Steinfield, C. and Lampe, C. 2011 . Connection strategies: social capital implications of Facebook-enabled communication practices. New Media E Society, 13, 6, 873-92.

Ellison, N. B., Vitak, J., Gray, R. and Lampe, C. 2014 . Cultivating social resources on social network sites: Facebook relationship maintenance behaviors and their role in social capital processes. Journal of Computer-mediated Communication, 19, 4, 855-70.

Erickson, L. B. 2011. Social media, social capital, and seniors: the impact of Facebook on bonding and bridging social capital of individuals over 65 . In King, N. (ed.), Proceedings of the 7th Americas Conference on Information Systems. AISeL, Atlanta, Georgia, 1-7.

Finch, B. and Vega, W. 2003. Acculturation stress, social support, and self-rated health among Latinos in California. Journal of Immigrant Health, 5, 3, 109-1 7 .

Fiori, K. L., Antonucci, T. C. and Cortina, K. S. 2006. Social network typologies and mental health among older adults. Journals of Gerontology: Psychological Sciences and Social Sciences, 61B, 1, P25-32.

Gibson, L., Moncur, W., Forbes, P., Arnott, J. L., Martin, C. and Bhachu, A. S. 2010. Designing social networking sites for older adults. In McEwan, T. and McKinnon, L. M. (eds), Proceedings of the 24th BCS Interaction Specialist Group Conference. British Computer Society, Swindon, UK, $186-94$.

Goode, L. 2011 . The motivations, connections and social capital of $55^{-64}$ year-olds on Facebook. In Threadgold, S., Kirby, E. and Germov, J. (eds), Proceedings of the Australian Sociological Association Conference. The University of Newcastle, Australia, 1-12.

Hawkley, L. C., Browne, M. W. and Cacioppo, J. T. 2005. How can I connect with thee? Let me count the ways. Psychological Science, 16, 10, 798-804.

Hawkley, L. C. and Cacioppo, J. T. 2010. Loneliness matters: a theoretical and empirical review of consequences and mechanisms. Annals of Behavioral Medicine, 4o, 2, 218-27. 
Haythornthwaite, C. 2005. Social networks and Internet connectivity effects. Information, Communication $\mathcal{E}$ Society, 8, 2, $125-47$.

Heeringa, S. and Connor, J. 1995. Technical Description of the Health and Retirement Survey Sample Design. University of Michigan, Ann Arbor, Michigan.

Joinson, A. N. 2008. 'Looking at', 'looking up' or 'keeping up with' people? Motives and use of Facebook. In Burnett, M., Costabile, M.F., Catarci, T., de Ruyter, B., Tan, D., Czerwinski, M. and Lund, A. (eds), Proceedings of the SIGCHI Conference on Human Factors in Computing Systems. ACM, New York, 1027-36.

Khvorostianov, N., Elias, N. and Nimrod, G. 2012. 'Without it I am nothing': the internet in the lives of older immigrants. New Media E Society, 14, 4, 583-99.

Lampe, C., Ellison, N. and Steinfield, C. 2006. A Face (book) in the crowd: social searching vs. social browsing. In Greenberg, S. and Mark, G. (eds), Proceedings of the 2oth Anniversary Conference on Computer Supported Cooperative Work. ACM, New York, 167-70.

Lang, F. R. 200o. Endings and continuity of social relationships: maximizing intrinsic benefits within personal networks when feeling near to death. Journal of Social and Personal Relationships, 1 7, 2, $155^{-82 .}$

Larson, R., Mannell, R. and Zuzanek, J. 1986. Daily well-being of older adults with friends and family. Psychology and Aging, 1, 2, 11 7-26.

Lee, B., Chen, Y. and Hewitt, L. 2011 . Age differences in constraints encountered by seniors in their use of computers and the internet. Computers in Human Behavior, 27, 3, $1231-37$.

Lehtinen, V., Näsänen, J. and Sarvas, R. 2009. A little silly and empty-headed: older adults' understandings of social networking sites. In Blackwell, A. (ed.), Proceedings of the 23 rd British HCI Group Annual Conference on People and Computers: Celebrating People and Technology. British Computer Society, Swindon, UK, $45^{-} 54$.

Lindley, S. E., Harper, R. and Sellen, A. 2009. Desiring to be in touch in a changing communications landscape: attitudes of older adults. In Greenberg, S., Hudson, S. E., Hinckley, K., Morries, M. R. and Olsen, D. R. (eds), Proceedings of the SIGCHI Conference on Human Factors in Computing Systems. ACM, New York, 1693-702.

Litwin, H. and Shiovitz-Ezra, S. 2011 . Social network type and subjective well-being in a national sample of older Americans. The Gerontologist, 51, 3, 379-88.

Lorenzo-Seva, U. and Ferrando, P. 20o6. FACTOR: a computer program to fit the exploratory factor analysis model. Behavior Research Methods, 38, 1, 88-91.

McWhirter, B. T. 1990. Factor analysis of the revised UCLA loneliness scale. Current Psychology, 9, 1, 56-68.

Mislevy, R. J. and Bock, R. D. 1990. BILOG 3: Item Analysis and Test Scoring with Binary Logistic Models. Scientific Software International, Chicago.

Muthén, L.K. and Muthén, B.O. 1998-2012. Mplus User's Guide. Seventh edition, Muthén \& Muthén, Los Angeles.

Peplau, L. A. and Perlman, D. 1982. Perspectives on loneliness. In Peplau, L. A. and Perlman, D. (eds), Loneliness: A Sourcebook of Current Theory, Research and Therapy. Wiley, New York, $1-18$.

Quinn, K. 2013. We haven't talked in 30 years! Information, Communication E⿱乛亅 Society, 16, 3, 397-420.

Robinson, J. P., Shaver, P. R. and Wrightsman, L. S. 1991. Criteria for scale selection and evaluation. In Robinson, J. P., Shaver, P. R. and Wrightsman, L. S. (eds), Measures of Personality and Social Psychological Attitudes. Academic Press, San Diego, California, 1-16.

Russel, D., Peplau, L. A. and Cutrona, C. E. 1980. The revised UCLA Loneliness Scale: concurrent and discriminant validity evidence. Journal of Personality and Social Psychology, 39, 3, 472-80. 
Seeman, T. E., Lusignolo, T. M., Albert, M. and Berkman, L. 2001. Social relationships, social support, and patterns of cognitive aging in healthy, high-functioning older adults: MacArthur studies of successful aging. Health Psychology, 2o, 4, 243-55.

Shanas, E. 1979. The family as a social support system in old age. The Gerontologist, 19, $2,169-74$.

Shiovitz-Ezra, S. and Ayalon, L. 2010. Situational versus chronic loneliness as risk factors for all-cause mortality. International Psychogeriatrics, 22, 3, 455-62.

Smock, A. D., Ellison, N. B., Lampe, C. and Wohn, D. Y. 2011 . Facebook as a toolkit: a uses and gratification approach to unbundling feature use. Computers in Human Behavior, 27, 6, 2322-9.

Sonnega, A., Faul, J. D., Ofstedal, M. B., Langa, K. M., Phillips, J. W. and Weir, D. R. 2014. Cohort profile: the Health and Retirement Study (HRS). International Journal of Epidemiology, 43, 2, 576-85.

Steptoe, A., Shankar, A., Demakakos, P. and Wardle, J. 2013. Social isolation, loneliness, and all-cause mortality in older men and women. Proceedings of the National Academy of Sciences, $110,15,5797-801$.

Sugisawa, H., Shibata, H., Hougham, G. W., Sugihara, Y. and Liang, J. 2002. The impact of social ties on depressive symptoms in U.S. and Japanese elderly. Journal of Social Issues, 58, $4,785^{-804}$.

Thoits, P. A. 1995. Stress, coping, and social support processes: Where are we? What next? Journal of Health and Social Behavior, 35, 53-79.

Tilvis, R. S., Kähönen-Väre, M. H., Jolkkonen, J., Valvanne, J., Pitkala, K. H. and Strandberg, T.E. 2004. Predictors of cognitive decline and mortality of aged people over a 1o-year period. Journals of Gerontology: Biological Sciences and Medical Sciences, 59A, 3, M268-74.

Timmerman, M. E. and Lorenzo-Seva, U. 201 1. Dimensionality assessment of ordered polytomous items with parallel analysis. Psychological Methods, 16, 2, 209-20.

Vitak, J. 2014. Facebook makes the heart grow fonder: relationship maintenance strategies among geographically dispersed and communication-restricted connections. In Morris, M. R. and Reddy, M. (eds), Proceedings of the I 7 th ACM Conference on Computer Supported Cooperative Work and Social Computing. ACM, New York, 842-53.

Weiss, R. S. 1973. Loneliness: The Experience of Emotional and Social Isolation. MIT Press, Cambridge, Massachusetts.

Weiss, R. 1974. The provisions of social relationships. In Rubin, Z. (ed.), Doing unto Others. Prentice-Hall, Englewood Cliffs, New Jersey, 1 7-26.

Xie, B., Watkins, I., Golbeck, J. and Huang, M. 2012. Understanding and changing older adults' perceptions and learning of social media. Educational Gerontology, $\mathbf{3}^{\mathbf{8}}$, $4,282-96$.

Accepted 2 June 2015; first published online 2 July 2015

Address for correspondence:

Rebecca P. Yu,

Communication Studies, University of Michigan,

5340 North Quad,

105 S. State Street,

Ann Arbor,

MI 48109 , USA

E-mail: rpyu@umich.edu 